J. Dairy Sci. 95:2765-2777

http://dx.doi.org/10.3168/jds.2011-4876

(C) American Dairy Science Association ${ }^{\circledR}, 2012$.

\title{
Recording of direct health traits in Austria-Experience report with emphasis on aspects of availability for breeding purposes
}

\author{
C. Egger-Danner, ${ }^{\star 1}$ B. Fuerst-Waltl, $\dagger$ W. Obritzhauser,‡ C. Fuerst, ${ }^{\star}$ H. Schwarzenbacher, ${ }^{\star}$ B. Grassauer,‡ \\ M. Mayerhofer, ${ }^{*}$ and A. Koeck ${ }^{2}$ \\ *ZuchtData EDV-Dienstleistungen GmbH, Dresdner Str. 89/19, 1200 Vienna, Austria \\ †Division of Livestock Sciences, Department of Sustainable Agricultural Systems, University of Natural Resources and Life Sciences Vienna, \\ Gregor-Mendel-Str. 33, 1180 Vienna, Austria \\ ¥Chamber of Veterinarians, Hietzinger Kai 87, 1130 Vienna, Austria
}

\section{ABSTRACT}

A project to establish an Austria-wide health-monitoring system for cattle was launched in 2006. Veterinary diagnostic data subject to documentation by law [Law on the Control of Veterinary Medicinal Products (Tierarzneimittelkontrollgesetz)] are standardized, validated, and recorded in a central database. This Austriawide project is a collaboration among agricultural and veterinary organizations as well as universities, and is also supported by the Austrian government. In addition to providing information for herd management and preventive measures, further objectives of the project include estimating breeding values for health traits and monitoring the overall health status of Austria's cattle. To ensure a high level of participation from farmers and veterinarians, data security issues are extremely important. Valid data are the prerequisite for the efficient use of health records. The challenge hereby is to distinguish between farms with low frequencies of diseases and incomplete documentation and recording. Measures were undertaken to establish a routine monitoring system for direct health traits. A routine genetic evaluation for direct health traits as part of the joint breeding value estimation program between Germany and Austria was introduced for Fleckvieh in December 2010, based on diagnostic data from 5,428 farms with 147,764 Fleckvieh cows. In 2010 to 2011, the reporting of direct health traits as a compulsory part of performance recording and the breeding program was introduced as well. The overall challenge is the availability of sufficient valid direct health data for reliable breeding values. Practical experience gained in Austria in setting up a health registration system,

\footnotetext{
Received August 26, 2011.

Accepted December 31, 2011.

${ }^{1}$ Corresponding author: egger-danner@zuchtdata.at

${ }^{2}$ Current address: Centre for Genetic Improvement of Livestock, University of Guelph, Guelph, Ontario N1G 2W1, Canada.
}

focusing mainly on the availability of direct health data for breeding purposes with its successes and difficulties, is described.

Key words: registration, health disorders, genetic selection

\section{INTRODUCTION}

Improved animal health is becoming increasingly important worldwide, because of its effect on farm economy and animal welfare, but also because food safety is of increasing interest to the consumer. The European Union Animal Health policy "Prevention is better than cure" (European Commission, 2007) emphasizes the importance of registering health data and using it for early detection of animal health problems.

Health issues may be addressed either directly or indirectly. Indirect parameters of health or disease have been included in routine recording systems by many countries. The importance of functional traits within total merit indices (TMI) is increasing worldwide. However, to increase the efficiency of genetic health improvement measures, directly observed indicators of health or disease need to be included in recording, evaluation, and selection systems.

Heringstad et al. (2003a) evaluated 2 Norwegian dairy cattle selection experiments. A high protein yield group and one low clinical mastitis group were introduced in 1989. Previously, from 1978 to 1989, groups were selected for high milk production and low milk production. Results showed that it is possible to obtain considerable selection response for clinical mastitis and that selection for increased milk production results in an unfavorable correlated increase in mastitis incidence, if mastitis is ignored in the breeding program. The results from the second selection experiment clearly demonstrate the positive effects of direct selection (Heringstad et al., 2007).

Philipsson and Lindhé (2003) reported a positive response to selection for mastitis resistance in all Nor- 
dic countries. The opportunities for genetic analysis, evaluation, and selection for reproduction and health traits depend on the development of integrated cattle databases.

For long-term enhancement of animal health, the genetic improvement of relevant traits is beneficial. A combination of direct and indirect health data are ideal. The lack of availability of reliable phenotypes for direct health traits very often restricts breeding for disease resistance with both traditional and advanced genomic methods. As the heritability for these traits is usually low, comprehensive and high-quality health data records are needed.

In the Scandinavian countries, direct health data has been routinely collected and used for years, with recording based on veterinary medical diagnoses (Nielsen et al., 2000; Forshell and Østerås, 2001; Heringstad et al., 2003b; Philipsson and Lindhé, 2003; Østerås and Sølverød, 2005; Aamand, 2006; Heringstad et al., 2007; Østerås et al., 2007; Johansson et al., 2008; Negussie et al., 2010). In many other countries, experience with direct health data is still limited, but interest in using recorded diagnoses or observations of disease has increased considerably in Austria (Egger-Danner et al., 2010a,b), Canada (Neuenschwander, 2010; Koeck et al., 2012), and the United States (Zwald et al., 2004a,b; Cole et al., 2006; Appuhamy et al., 2009).

The basic concept of the Austrian project "Health monitoring in cattle" follows the Scandinavian approach, where reporting of health data are carried out in close cooperation with veterinarians. In Austria, recording of diagnostic data and treatments has been required by law since 2002. Before the project started in Austria in 2006, the data was neither standardized, nor routinely collected and stored in a common database, and could not, therefore, be used for breeding and management purposes. In Austrian cattle breeds, functional traits have a relative economic weight of almost $50 \%$ within the TMI. However, so far no direct health data has been included in breeding value estimation for functional traits. For mastitis and fertility, the auxiliary traits SCC and traits based on insemination and calving have been considered, respectively.

The project objectives are to develop and implement a system to collect diagnostic data, providing reports for herd management and preventive measures, and estimating breeding values for direct health traits and key parameters for the monitoring of health status. The cooperation between agricultural and veterinary organizations has also been strengthened by working together on this project.

This paper describes the concept, parameters, and practical experience gained in $4 \mathrm{yr}$ of implementation of the project. Special attention is paid to the aspects of using the recorded data for breeding purposes.

\section{MATERIALS AND METHODS}

\section{Project Organization and Time Frame}

Under the leadership of the Federation of Austrian Cattle Breeders (ZAR, Vienna, Austria), a healthmonitoring system was developed and implemented in close cooperation with several organizations involved in animal health issues: the Ministry for Agriculture, Forestry, Environment and Water Management (Vienna, Austria); the Ministry for Health (Vienna, Austria); the University of Veterinary Medicine Vienna; the University of Natural Resources and Life Sciences Vienna; local animal health organizations; the Chamber of $\mathrm{Ag}$ riculture (Vienna, Austria); and the Chamber of Veterinarians (Vienna, Austria). The Federation of Austrian Cattle Breeders, also representing performance recording and breeding organizations, is the organization in charge of executing the project.

The project was managed by a steering committee. Temporary working groups were set up to develop different project aspects (e.g., health reports, breeding values, and training modules).

The project officially started in 2006. The design of the project and preparation was carried out in 2005 and early 2006. The different measures carried out within the project are listed in Table 1. In 2010, the main emphasis was on implementation of the measures into practitioners' routines.

\section{Health Data Recording}

Motivation and Information. To encourage farmers and veterinarians to adopt any new technology, they must be informed and made aware of possible benefits. The employees of performance-recording organizations (EPO) were given the task of convincing farmers to join the project. Veterinarians were informed by their Chamber and local animal health organizations. Before starting the information campaign, employees of the EPO and representatives from the other partner organizations were trained to effectively present the necessary information.

Legal Framework. Based on the Law on the Control of Veterinary Medicinal Products (Tierarzneimittelkontrollgesetz), diagnoses have had to be documented upon receipt of medications since 2002. Due to a bylaw on veterinary drug residue testing, all treatments and prescriptions have to be recorded in a log at the farm. 
Table 1. Time frame of implementation $(\mathrm{x})$ of different measures within the project ${ }^{1}$

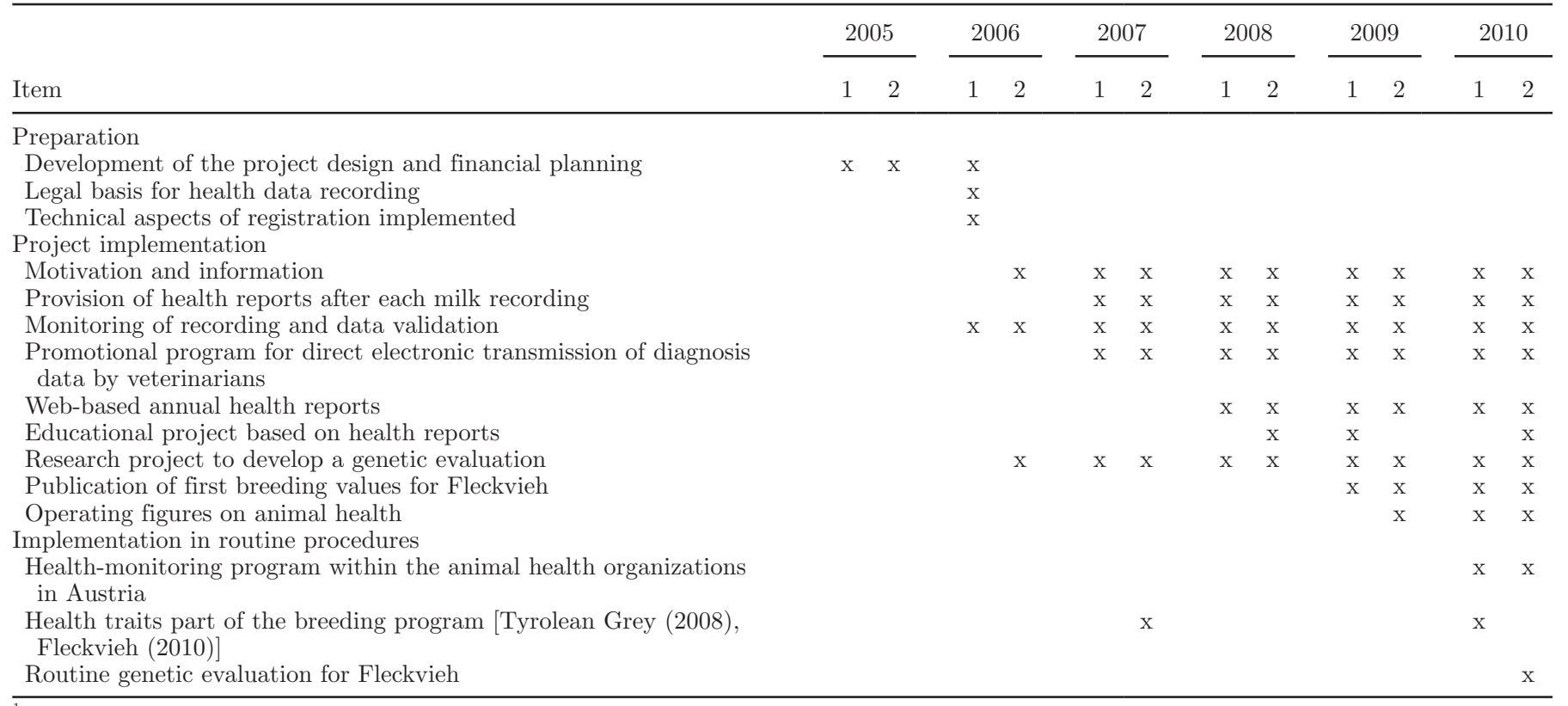

${ }^{1}$ Where 1 and 2 in each year refer to first and second half of each year, respectively.

A standardized key for diagnoses was developed for the project and was published by the Ministry of Health before the start of the project in 2006 .

Data Type and Standardization of Diagnoses. Diagnostic data are standardized by veterinarians using a coding system consisting of 65 diagnoses divided into 10 categories. This coding system only includes diseases relevant for breeding purposes, which can be diagnosed on site by the veterinarians, but currently no laboratory results. A 2-digit code for the standardized diagnosis was added to the receipt for the documentation of medication (Law on the Control of Veterinary Medicinal Products).

Udder health traits recorded are divided into clinical mastitis (CM), which is subdivided into acute mastitis (AcM) and chronic mastitis (CrM), diseases of the udder and the teat, udder edema, and other udder diseases. In addition, preventive measures for drying off have been recorded since 2008. Fertility disorders are divided into metritis (MET), silent heat (ESTR), cystic ovaries (CYST), retained placenta (RP), puerperal diseases (PUERP), and other categories such as calving injuries and other injuries. The traits milk fever (MF) includes metabolic diseases caused by hypercalcemia, hypophosphatemia, or hypomagnesemia. Furthermore, feet and leg diseases, digestive disorders, special diseases of the calves, as well as respiratory diseases and diseases of the heart, circulation, and diseases regarding skin disorders, central nervous system, infections, or other diseases are covered within the standardized diagnoses (Austrian Ministry of Health,
2010). The number of the farm, the identification of the animal, the date, and the 2-digit code of the diagnosis and the identification of the veterinarian are recorded with every treatment and prescription.

Data Collection and Data Storage. Diagnostic data are recorded into the Austrian central cattle database. This has the advantage that validation checks can be done using the information gathered from identification and performance recording. Philipsson and Lindhé (2003) stress the importance of complex databases for the use of data. Within the course of each disease, the diagnosis is only recorded once (course diagnosis). It is not mandatory to record the veterinarian's identification. A plausibility check is carried out before storage in the database. This includes checks concerning the identification of the animal and the herd as well as the course of the disease. Several diagnoses are recorded only once per lactation, such as MF, MET, RP, among others. For other diagnoses, a new case of the same diagnosis can be recorded after a specified minimum period [e.g., CYST (21 d) and AcM (7 d); Austrian Ministry of Health, 2010].

Data may be transmitted electronically by the veterinarians via an interface or recorded by the employees of EPO (Figure 1). A one-time payment of $€ 200$ was provided to motivate veterinarians to update their software for direct transmission of the diagnostic data. In addition, $€ 0.10$ is paid per electronically submitted diagnosis during the course of a treatment by public authorities, as they are interested in information to monitor the health status. 


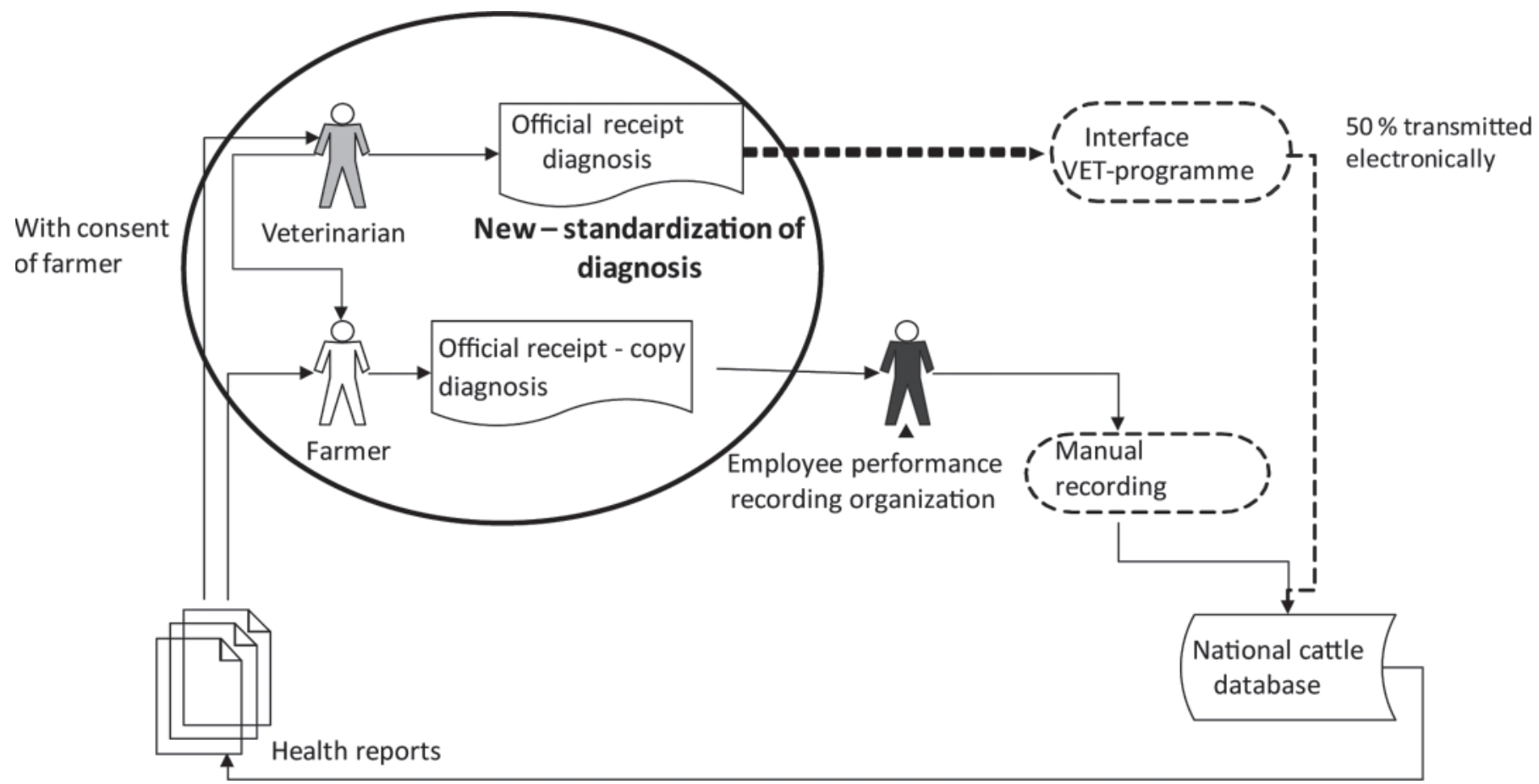

Figure 1. Recording of diagnostic data. VET = vocational education and training.

Data Security. Health data are very sensitive and, therefore, data security for farmers and veterinarians has to be guaranteed and given highest priority. Before recording the data into the database, the farmers are required to sign a release explicitly stating the possible use of data. The farmer has to agree to provision of the health reports to veterinarians. The farmer only has access to the diagnosis registered at his own farm. The veterinarian identification is stored in the database without a link to the person, making it impossible to trace data back to an individual veterinarian.

Data Validation. Good data quality is necessary if any benefits are to be gained from health data. In addition to plausibility checks, the use of health reports by farmers and veterinarians is an important contribution to data quality, as incorrect documentation and recording of diagnostic data can be recognized. From a data validation perspective, the return flow of information is essential. In general, differentiating between farms with incomplete diagnosis data and farms with very low incidence rates is a challenge. Only data from farms fulfilling strict criteria on the regular and complete registration of diagnoses are included in the genetic analysis (Egger-Danner et al., 2009; Koeck et al., 2010a,b,c). Emphasis is placed on defining the observation period specific to each farm. This takes certain variables into account (e.g., if a veterinarian stops the electronic submission of the data). Additionally, for each cow, a valid time period under observation is defined (e.g., information about calving, type of use, and change of farm is considered). Based on this information, an average of diagnoses per cow and year is calculated. A minimum of 0.1 diagnoses per cow and year is required. For calculation of incidence rates used for monitoring the animal health status by the Ministries, diagnostic data are restricted only to electronically transmitted diagnoses.

\section{Health Reports}

Optimized herd management is important for economically successful farming. To recognize problems early, additional health information is valuable. Therefore, diagnostic data was added to the already existing reports provided to the farmer after each milk recording to give additional health information. Additionally, besides dairy cows, all other age groups as well as males and females were considered. In addition, annual reports including benchmarks were developed, enabling the farmer to compare farm results to the previous year's results, as well as to average results on district and province levels. A graphical comparison based on percentiles is also available (Schwarzenbacher et al., 2010). An internet-based tool provides annual reports, with information updated daily (Austrian Ministry of Health, 2010). The veterinarian can access this information if the farmer agrees. These annual reports are also used by veterinarians for their evaluation of the 
overall herd health status of the supervised cattle herds within the animal health organization.

For the interpretation of the health reports, a special training program was implemented. It became obvious that many farmers lacked the knowledge to interpret and work with this comprehensive data. Based on these health reports, each farmer was asked to develop an individual plan of action, and 6,500 farmers participated.

\section{Operating Figures on Health Status}

The Ministries and the animal health organizations are interested in obtaining anonymous reports on animal health status and on the frequency of occurrence of diagnoses on a regional and national level. The key figures are the incidence rate (IR) and the number of course diagnoses per 100 cows. The population at risk is defined as the number of animals under valid disease recording and defined observation (obs.) period.

The IR is calculated as follows:

$\mathrm{IR} / \mathrm{yr}=$

newly diseased individuals during obs. period

sum of obs. periods (in years) across all individuals in population

The analysis provided here is comparable to the current analysis of Kelton et al. (1998), which accounts for all events and cows at risk within a recent period.

\section{Genetic Evaluation}

One major project objective is to provide breeding values for direct health traits for sires. Detailed analyses were carried out by Koeck et al. (2010a,b,c) about trait definition and genetic parameters for direct health traits based on diagnostic data from the Austrian health-monitoring system for Fleckvieh.

Traits for Routine Genetic Evaluation. The traits included are CM, with an observation period of between -10 to $150 \mathrm{~d}$ after calving, early reproductive disorders (EREPRO) for the period between calving and $30 \mathrm{~d}$ after calving, CYST for the period between 30 and $150 \mathrm{~d}$ after calving, and MF for the period of $10 \mathrm{~d}$ before and $10 \mathrm{~d}$ after calving. Culling due to the specified complex within the observation period is considered a diagnosis (Fuerst et al., 2011). It might be that a cow is not treated before culling in case of a severe health disorder.

Data. In December 2010, a routine genetic evaluation for direct health traits was introduced for the Fleckvieh breed as part of the joint genetic evaluation program between Germany and Austria (Fuerst et al., 2011). Presently, only Austrian data are included.
Baden-Württemberg and Bavaria in Southern Germany started setting up direct health trait reporting systems in 2010 .

Model for Routine Genetic Evaluation. The genetic evaluation for health traits is based on a linear univariate BLUP animal model carried out with the program MiX99 (Lidauer et al., 2008). The calculation of reliability is done with the program ApaX (Strandén et al., 2001) based on the approach described by Tier and Meyer (2004). The statistical model includes the following effects:

$$
\begin{gathered}
\mathrm{y}_{\mathrm{ijklmnopq}}=\mathrm{LACT}_{\mathrm{i}} \times \mathrm{AGE}_{\mathrm{j}}+\mathrm{YR}_{\mathrm{k}} \times \mathrm{MO}_{\mathrm{l}}+\mathrm{REC}_{\mathrm{m}} \\
\times \mathrm{YR}_{\mathrm{k}}+\mathrm{H}_{\mathrm{n}} \times \mathrm{YR}_{\mathrm{k}}+\mathrm{PE}_{\mathrm{o}}+\mathrm{a}_{\mathrm{p}}+\mathrm{e}_{\mathrm{ijklmnopq}},
\end{gathered}
$$

where $\mathrm{y}_{\mathrm{ijk} \text { klmnopq }}$ is the observation for CM, EREPRO, CYST, and MF $(0=$ healthy, $1=$ diseased $) ; \mathrm{LACT}_{\mathrm{i}} \times$ $\mathrm{AGE}_{\mathrm{j}}$ is the fixed effect of parity $(1,2, \ldots, 5+)$ by calving age (6 classes for first and second parity each); $\mathrm{YR}_{\mathrm{k}}$ $\times \mathrm{MO}_{1}$ is the fixed effect of calving year and month; $\mathrm{REC}_{\mathrm{m}} \times \mathrm{YR}_{\mathrm{k}}$ is the fixed effect of type of recording (electronic/milk recording) by year; $\mathrm{H}_{\mathrm{n}} \times \mathrm{YR}_{\mathrm{k}}$ is the random herd-year effect; $\mathrm{PE}_{\mathrm{o}}$ is the random permanent environmental effect; $a_{p}$ is the random genetic effect of the animal; and $\mathrm{e}_{\mathrm{ijklmnopq}}$ is the random residual effect.

The 2 types of recording methods are direct electronic submission, done by the veterinarian, and registration by the EPO. If more than $50 \%$ of the diagnoses are recorded by the EPO, the effect of the employee is added to the model. If more than $50 \%$ of the diagnoses are transmitted electronically for farms with more than 20 cows, the model differentiates between 50 and $75 \%$ and above $75 \%$. The fixed effect of type of recording by year accounts for changing environmental effects. Due to small herd sizes in Austria a random herd $\times$ year effect can be of advantage according to Visscher and Goddard (1993). Because of limited availability of data a repeatability model is used presently. Recent studies show that both possibilities are justified (Pritchard et al., 2011; Urioste et al., 2011). More detailed information is available in the work of Fuerst et al. (2011).

\section{RESULTS AND DISCUSSION}

\section{Health Data Registration}

The Austrian health-monitoring system is open to all regions and covers all cattle breeds. So far, the main focus has been on dairy cows only. The distribution of herd book cows in the main breeds in Austria are as follows: Fleckvieh $(273,000)$, Brown Swiss $(55,000)$, Holstein (40,000), Pinzgau cattle (7,700), and Tyrolean Grey $(3,800)$. 
Table 2. Total number of dairy farms (DF; all breeds) in the Austrian Dairy Herd Recording System, development of percentage of farms participating in the health monitoring (HM), and farms with veterinary diagnosis data in the database (HMVDR $)^{1}$

\begin{tabular}{|c|c|c|c|c|c|c|c|c|c|c|c|}
\hline \multirow[b]{2}{*}{ Region } & \multirow[b]{2}{*}{$\begin{array}{l}\text { No. of DF } \\
\text { in } 2010\end{array}$} & \multicolumn{5}{|c|}{ HM DF (\%) } & \multicolumn{5}{|c|}{ HMVDR DF (\%) } \\
\hline & & $\begin{array}{l}\text { Feb. } \\
2011\end{array}$ & $\begin{array}{l}\text { Feb. } \\
2010\end{array}$ & $\begin{array}{l}\text { Feb. } \\
2009\end{array}$ & $\begin{array}{l}\text { Feb. } \\
2008\end{array}$ & $\begin{array}{l}\text { Feb. } \\
2007\end{array}$ & $\begin{array}{l}\text { Feb. } \\
2011\end{array}$ & $\begin{array}{l}\text { Feb. } \\
2010\end{array}$ & $\begin{array}{l}\text { Feb. } \\
2009\end{array}$ & $\begin{array}{l}\text { Feb. } \\
2008\end{array}$ & $\begin{array}{l}\text { Feb. } \\
2007\end{array}$ \\
\hline Best region & & 77 & 78 & 77 & 77 & 76 & 91 & 90 & 80 & 64 & 21 \\
\hline Worst region & & 3 & 1 & 1 & 0 & 0 & 43 & 50 & 50 & 0 & 0 \\
\hline Austria & 23,177 & 64 & 54 & 48 & 42 & 37 & 62 & 66 & 61 & 50 & 23 \\
\hline
\end{tabular}

${ }^{1}$ The Austrian average and the recent results are indicated in bold.

Participation. In most regions, the project to establish an Austria-wide health monitoring system started between September and December 2006. Table 2 shows the impact of implementation from 2007 to 2011. A total of 15,008 farms with 220,000 cows were participating as of February 2011, which accounts for $64 \%$ of all dairy herds under performance recording.

Some regions achieved a very high participation level within a few months with slow, but steadily increasing support from veterinarians. The best regions reached a voluntary participation level of close to $80 \%$. Currently about 80 to $90 \%$ of these farms are providing veterinary diagnoses, which is approximately $70 \%$ of all healthregistered cows. In one region, the project did not get started effectively. The most essential prerequisite is the support of the opinion leaders in both agricultural and veterinarian organizations. Surveys of farmers on their future breeding emphasis demonstrate the desire to improve fertility and udder health in particular. Nevertheless, regular information is needed to encourage confidence and to convince practitioners of the benefits. During the project, progress reports were provided on a regular basis. Farmers and veterinarians were asked to share their experiences about the project.

The participative approach is a further important element for a successful outcome. It is important that, starting from the project design all the way to implementation, the partners involved in cattle health issues are encouraged to participate and actively contribute. It is essential that key players (i.e., farmers and veterinarians) are made aware of the benefits. Strong emphasis must be placed on data security and data validation. The technical implementation has to take the needs and concerns of the target groups into account. To obtain sufficient data for breeding purposes, it is important that several data sources and different data-recording methods are available. Regional circumstances and the available infrastructure must also be taken into consideration (Egger-Danner et al., 2011a).

Data Validation. The results show that not all of the farms that participate in health monitoring already have diagnoses stored in the database. In addition, it seems that reporting of diagnoses is not carried out on a regular basis in some herds. The evaluation of the official breeding value estimation in April 2011 shows that out of 23,177 dairy farms under performance recording, 14,866 are participating in the health-monitoring program, and that 9,194 had at least 1 diagnosis recorded in the cattle database. This is due to a delay in the start of documentation and recording of veterinary coded diagnoses, but it might also be that standardized veterinary diagnoses documented upon receipt of medications are not available or recording is not properly done. Within the project, no other information about health disorders was used.

Herds that did not meet the criteria of a minimum of 0.1 course diagnoses per cow across the observation period were excluded, as well as farms in which only 1 diagnosis was recorded. In Denmark, the limit is 0.3 diagnoses per cow and year, but no restriction exists on course diagnoses only (Interbull, 2011). At least 200 first diagnoses per veterinarian or per EPO is a prerequisite for successful validation. This explains the delay from the start of recording until farms are included in the genetic evaluation. The definition of the observation period is important, especially if the system is newly established and not entirely stable. Experience has shown that regular reporting cannot be taken for granted right from the beginning.

After validation, 6,753 farms (5,672 Fleckvieh herds) remained for genetic evaluation. Currently, $27 \%$ of the farms with recorded diagnoses do not meet the various validation requirements. Major regional differences exist in the percentage of farms that fulfill the validation criteria. In the best regions, about $87 \%$ of the farms with recorded diagnoses were included. Due to the small average herd size (17 cows; ZuchtData, 2010), it is possible that not all diseases occur in all herds. Hence, no criteria were applied for individual diseases. Zwald et al. (2004a) had different percentages of usable herds in the United States (47\% ketosis, 59\% mastitis, 41\% CYST, and 65\% MET). Neuenschwander (2010) reported that not all farms record all diagnoses in Canada. It might also be that farmers emphasize different 
health aspects at different times. This is more relevant for reporting systems where no legal documentation is required.

A survey of 600 farms showed that despite promotion, not all farms or their veterinarians are providing reliable health data. The main reasons for incomplete data mentioned were missing documentation in general, missing standardization, or that not all documentation available for recording diagnoses was provided by the EPO. However, with awareness-building activities and regular information, data quality could be improved.

\section{Operating Figures on Health Status}

Distribution and Time of Occurrence of Diseases. Analyses of the frequency and occurrence of diseases (Tables 3 and 4) included data from dairy cows, without restriction to breed. As registration of diagnoses started in late 2006 and is still continuing, all available validated diagnostic data were included for this time period. The calculation of the distribution of all registered diseases was based on valid herds and restricted to herds with at least 10 cows (Table 3). All course diagnoses of dairy cows, independent of breed and independent of the stage of lactation, were included. No restrictions with regard to time before or after calving were applied.

The calculation was done for disease complexes as well as for the most frequently occurring single diagnoses. Most of the diagnoses were observed for fertility and udder complexes. Within the first lactation, $42.6 \%$ of the diagnoses of dairy cows concerned reproduction, and $31.9 \%$ were udder disorders, whereas only $3.0 \%$ of all diagnoses of cows were digestive and metabolic diseases. Reproduction disorders decreased across lactations. In later lactations, the relative percentage of udder, digestive, and metabolic disorders increased. The number of diagnoses per parity did not directly reflect the age distribution of the Austrian dairy populations, as the number of diagnoses was increased in later lactations.

Table 4 shows the distribution of the most frequent diagnoses across lactations that occurred between $10 \mathrm{~d}$ before and $300 \mathrm{~d}$ after calving. Only diagnoses of dairy cows were considered. This information is relevant for the trait definition for genetic evaluation and recording methods. Retained placenta, puerperal diseases, and MF occur shortly after calving. Therefore, these traits could also be registered together with data on ease of calving.

Appuhamy et al. (2009) did not differentiate between different reproductive disorders. For general reproduction, $67 \%$ of all reproductive disorders occurred within the first month of lactation. Zwald et al. (2004a) showed that $60 \%$ of MET cases were within the first 30 DIM and CYST mainly occurred between 30 and $150 \mathrm{~d}$. Both studies found that ketosis occurred within the first 30 d in $90 \%$ of cases. Their results for lameness differed from the results found for panaritium/dermatitis digitalis and sole ulcer. For lameness, no higher frequency within the first months of lactation was observed.

For mastitis, a system for regular reporting is important. The high level of CrM at the end of the lactation period may have been overestimated, because in the beginning of the project the application of antibiotics for drying off was frequently registered as CrM due to

Table 3. Distribution of most commonly recorded diagnoses of dairy cows, based on validated data for different lactations (lact), in percent (all breeds) between 2006 and $2011^{1}$

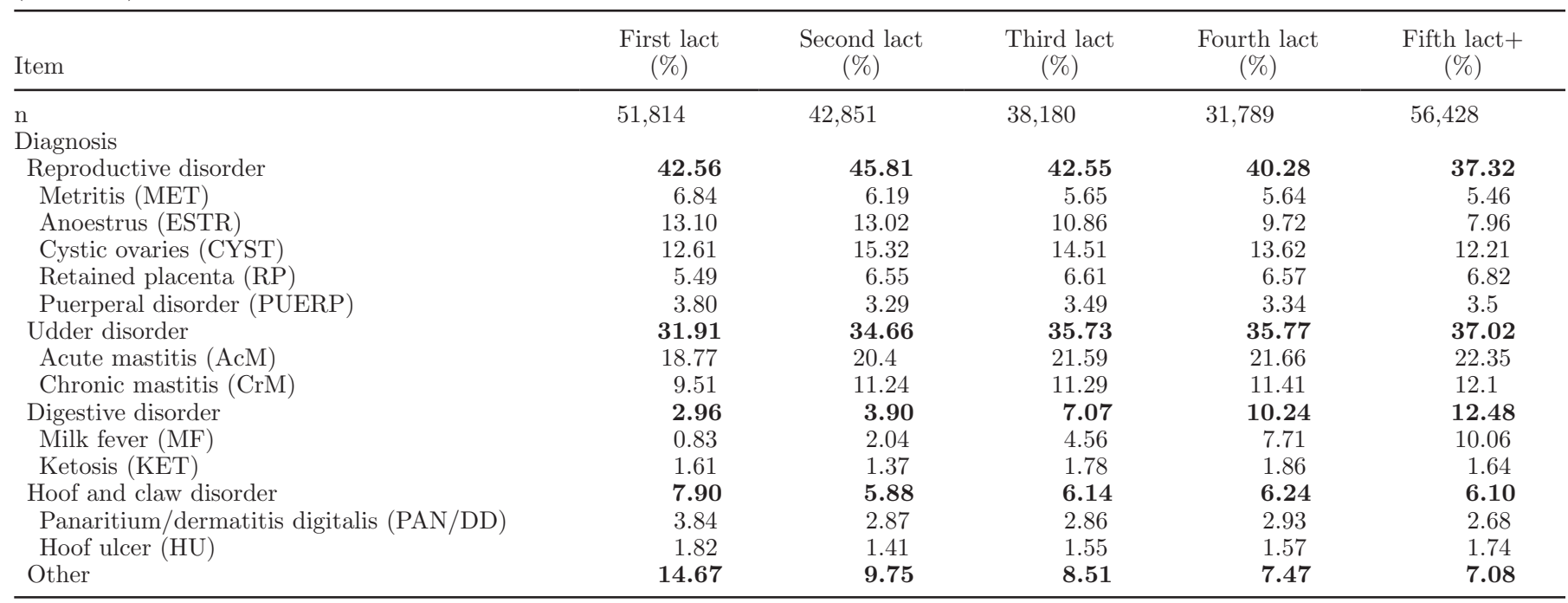

\footnotetext{
${ }^{1}$ The summaries of the different trait complexes are indicated in bold.
} 
Table 4. Stage of lactation, measured as days after calving for first incidence (\%) of single health disorders across lactations and breeds based on validated data between 2006 and 2011

\begin{tabular}{|c|c|c|c|c|c|c|c|c|c|c|c|}
\hline \multirow[b]{2}{*}{ Item } & \multicolumn{11}{|c|}{ Health disorder ${ }^{1}$} \\
\hline & MET & ESTR & CYST & $\mathrm{RP}$ & PUERP & $\mathrm{AcM}$ & $\mathrm{CrM}$ & MF & KET & $\mathrm{PAN} / \mathrm{DD}$ & SU \\
\hline $0-30$ & 45.6 & 3.7 & 4.5 & 96.3 & 91.7 & 32.1 & 22.5 & 96.0 & 67.9 & 26.0 & 26.6 \\
\hline $30-60$ & 22.6 & 17.1 & 24.2 & 0.6 & 2.9 & 12.9 & 11.0 & 0.7 & 18.9 & 16.0 & 15.5 \\
\hline $60-90$ & 11.0 & 26.7 & 25.2 & 0.3 & 1.5 & 11.2 & 9.6 & 0.7 & 5.2 & 10.5 & 10.8 \\
\hline $150-180$ & 3.2 & 8.4 & 7.5 & 0.1 & 0.3 & 6.9 & 6.3 & 0.2 & 1.6 & 6.8 & 6.0 \\
\hline $180-210$ & 2.2 & 5.7 & 4.6 & 0.2 & 0.3 & 5.8 & 5.7 & 0.3 & 0.8 & 6.7 & 5.6 \\
\hline $210-240$ & 1.4 & 3.6 & 2.9 & 0.3 & 0.3 & 5.1 & 5.4 & 0.5 & 0.7 & 6.0 & 5.5 \\
\hline $240-270$ & 1.1 & 2.1 & 1.8 & 0.8 & 0.8 & 4.2 & 7.3 & 0.4 & 0.4 & 6.3 & 5.7 \\
\hline $270-300$ & 0.8 & 1.4 & 1.1 & 1.1 & 0.8 & 4.5 & 16.5 & 0.5 & 0.3 & 5.7 & 5.4 \\
\hline
\end{tabular}

${ }^{1} \mathrm{MET}=$ metritis; ESTR = anestrus; CYST = cystic ovaries; RP = retained placenta; PUERP = puerperal diseases; AcM = acute mastitis; CrM $=$ chronic mastitis; $\mathrm{MF}=$ milk fever; KET $=$ ketosis; $\mathrm{PAN} / \mathrm{DD}=$ panaritium/dermatitis digitalis; $\mathrm{SU}=$ sole ulcer.

a missing diagnosis code. This was introduced in 2008 . Therefore, genetic evaluation only takes the period up to $150 \mathrm{~d}$ postpartum (dpp) into consideration.

Koeck et al. (2010b) and Zwald et al. (2006) estimated heritability for mastitis for different time periods. According to Koeck et al. (2010b), heritability between -10 to $50 \mathrm{dpp}$ was higher as compared with between 50 and $150 \mathrm{~d}$ of lactation. Zwald et al. (2006) showed a higher heritability in the first lactation, but otherwise similar estimated values for different lactation stages. The studies by Zwald et al. (2004a) and Appuhamy et al. (2009) showed a higher number of mastitis cases at the beginning of the lactation.

Incidence of Diagnoses. The incidence rates presented in the current study (Table 5) were calculated for the year 2010, and included all herds and dairy cows that met the validation criteria. The average number of course diagnoses per cow and year was 0.727 if data were mainly $(\geq 75 \%)$ submitted electronically directly by the veterinarian. The validated data sets for genetic evaluation showed an average of 0.496 course diagnoses per cow and year across all breeds. Only diagnostic data based on documentation requirements pursuant to the Law on the Control of Veterinary Medicinal Products were included. No additional information from the farmers was considered. Table 5 shows incidence rates based on the year 2010 according to different data registration methods (electronic versus on-site). Table 5 is not restricted to a specific breed. Incidence rates were comparable for some diagnoses. This was especially the case for diagnoses for which antibiotic treatment is common (AcM and RP). The incidence rate of MF and ovarian cysts was considerably lower if data were recorded mainly by EPO, probably because treatments that did not require restrictions for the delivery of milk were not reported completely. Therefore, for some diagnoses, a system based only on documentation of medication use might not be comprehensive enough. It may also be that those veterinarians using electronic devices documented the use of drugs more comprehensively. Additionally, they might have contracts with the farmers, which include more regular observation of the animals' fertility status (e.g., regular ultrasound examinations), leading to a higher number of diagnoses.

Based on these differences, the reporting method is an important parameter to be included in the model for genetic evaluation. In the future, additional information will be requested by the farmer (e.g., when reporting ease of calving, the farmer will be asked whether RP, MF, mastitis, or lameness has occurred around calving). If incidence rates are calculated without taking different environmental circumstances into account, it is advisable to restrict those calculations to an even stricter validation than for genetic evaluation. Initial operating figures, on regional and national levels, have been provided based on electronically submitted validated diagnostic data only.

\section{Genetic Evaluation}

Diagnostic data are collected for all breeds, but so far, data are sufficient only for routine genetic evaluation for Fleckvieh. Therefore, analyses concerning genetic evaluation include only diagnostic data from Fleckvieh (Tables 6-8). About 370,000 Fleckvieh lactation records were included in the genetic evaluations as of April 2011 (Table 6) compared with 345,791 lactation records from 5,428 farms with 147,764 Fleckvieh cows in December 2010.

Genetic Parameters. Genetic parameters were evaluated with threshold as well as linear models (Koeck et al., 2010a,b,c; Fuerst et al., 2011). For com- 
Table 5. Incidence rates based on different data registration methods across breeds for dairy cows under observation in $2010^{1}$

\begin{tabular}{lccc}
\hline & \multicolumn{2}{c}{$\begin{array}{c}\text { Incidence rate in 2010 based on } \\
\text { different validated data sets }\end{array}$} \\
\cline { 2 - 4 } Item & EPO & GE & VET \\
\hline Number of cows in calculation & 39,279 & 76,314 & 21,205 \\
Diagnosis & & & \\
Reproductive disorder & $\mathbf{1 4 . 5 0}$ & $\mathbf{1 8 . 6 2}$ & $\mathbf{2 8 . 1 3}$ \\
Metritis (MET) & 2.26 & 3.30 & 5.18 \\
Anestrus (ESTR) & 3.83 & 5.51 & 8.61 \\
Cystic ovaries (CYST) & 4.72 & 7.10 & 12.70 \\
Retained placenta (RP) & 3.97 & 3.49 & 2.97 \\
Puerperal disorder (PUERP) & 0.56 & 1.48 & 3.50 \\
Udder disorder & $\mathbf{1 3 . 5 3}$ & $\mathbf{1 4 . 3 2}$ & $\mathbf{1 7 . 0 1}$ \\
Acute mastitis (AcM) & 9.65 & 10.16 & 11.01 \\
Chronic mastitis (CrM) & 3.67 & 4.02 & 5.99 \\
Hoof and claw disorder & $\mathbf{3 . 2 7}$ & $\mathbf{3 . 7 5}$ & $\mathbf{5 . 0 5}$ \\
Panaritium/dermatitis digitalis (PAN/DD) & 1.61 & 1.96 & 2.93 \\
Hoof ulcer (HU) & 1.07 & 0.95 & 0.79 \\
Digestive disorder & $\mathbf{2 . 5 6}$ & $\mathbf{3 . 2 3}$ & $\mathbf{4 . 9 1}$ \\
Milk fever (MF) & 1.94 & 2.46 & 3.80 \\
Ketosis (KET) & 0.41 & 0.56 & 0.86 \\
\hline
\end{tabular}

${ }^{1}$ The summaries of the different trait complexes are indicated in bold.

${ }^{2} \mathrm{EPO}=$ recording by employee of a performance-recording organization with less than $25 \%$ of diagnostic data submitted electronically; $\mathrm{GE}=$ genetic evaluation; VET = more than $75 \%$ of diagnostic data submitted electronically.

parability, heritability estimates from the linear models can be transformed from the observable $(0 / 1)$ scale to the underlying scale using the formula of Dempster and Lerner (1950). Based on a threshold sire model, the heritability values were RP, 0.060; PUERP, 0.143; MET, 0.062; ESTR, 0.012; CYST, 0.077; and EREPRO, 0.079 (Koeck et al., 2010a). For CM ( -10 till $150 \mathrm{~d}$ after calving), Koeck et al. (2010b) estimated a heritability of 0.060 based on a probit threshold sire model, based on a linear animal model of 0.019. Genetic correlations were estimated by Koeck et al. (2010c). The genetic correlation between SCC and CM was between 0.64 and 0.77. Fuerst et al. (2011) estimated a heritability for MF of 0.036 with a linear animal model and VCE6 (Groeneveld et al., 2008). Based on a linear animal model, heritability values according to Koeck et al. (2010a,b) ranged from 0.006 for anestrus (ESTR) to 0.040 for CYST. The correlation between RP, PUERP, and MET was 1 . Therefore, the traits were combined into early reproductive disorders with a heritability of 0.023 (linear model). Heritability for reproductive diseases and mastitis based on this diagnostic data are comparable with that of analyses of health data by Nielsen et al. (2000), Zwald et al. (2004a,b, 2006), Heringstad et al. (2005), Johansson et al. (2006, 2008), and Negussie at al. (2010).

The EBV for health traits are defined as relative breeding values, with an average of 100 and a genetic standard deviation of 12 points. A higher breeding value is desirable. Estimated breeding values are published with a minimum reliability of $30 \%$. The number of bulls that have been assigned official EBV ranges

Table 6. Number of observations (n), average incidence of disorders (Avg. inc.), and number of bulls with breeding values depending on different reliabilities for Fleckvieh ${ }^{1}$

\begin{tabular}{lccccc}
\hline Disorder $^{2}$ & $\mathrm{n}$ & $\begin{array}{c}\text { Avg. inc. } \\
(\%)\end{array}$ & $\begin{array}{c}\text { No. of bulls } \\
\text { with } \mathrm{R}^{2}>30 \%\end{array}$ & $\begin{array}{c}\text { No. of bulls } \\
\text { with } \mathrm{R}^{2}>50 \%\end{array}$ & $\begin{array}{c}\text { No. of bulls } \\
\text { with } \mathrm{R}^{2}>70 \%\end{array}$ \\
\hline CM (-10 to 150 dpp) & 366,853 & 9.8 & 1,832 & 408 & 187 \\
EREPRO (-30 dpp) & 368,530 & 5.0 & 2,094 & 469 & 214 \\
CYST (30 to 150 dpp) & 374,070 & 5.4 & 2,978 & 927 & 342 \\
MF (-10 to 10 dpp) & 373,184 & 2.4 & 2,816 & 790 & 307 \\
\hline
\end{tabular}

${ }^{1}$ Routine genetic evaluation in April 2011.

${ }^{2} \mathrm{CM}(-10$ to $150 \mathrm{dpp})=$ clinical mastitis between $10 \mathrm{~d}$ before and $150 \mathrm{~d}$ after calving (days postpartum, dpp); EREPRO $(-30 \mathrm{dpp})=$ early reproductive disorders up to $30 \mathrm{~d}$ after calving; CYST $(30-150 \mathrm{dpp})=$ cystic ovaries between 30 and $150 \mathrm{~d}$ after calving; MF ( -10 to $10 \mathrm{dpp})=$ milk fever between $10 \mathrm{~d}$ before and $10 \mathrm{~d}$ after calving. 
Table 7. Distribution of bulls with breeding values for clinical mastitis (CM) and early reproductive disorders (EREPRO) in the total merit index (TMI) for Austrian Fleckvieh bulls (TMI_75AUT ${ }^{1}$ ) and Fleckvieh bulls from Germany and Austria (TMI_75ALL ${ }^{2}$ ), with a minimum reliability of 30 and 50\%, according to birth year

\begin{tabular}{lcccccc}
\hline & \multicolumn{5}{c}{ Bull distribution category $^{3}$} \\
\cline { 2 - 6 } Birth year & TMI_75ALL & TMI_75AUT & CM_30 & CM_50 & EREPRO_30 & EREPRO_50 \\
\hline$\leq 1990$ & 5,630 & NI $^{4}$ & 250 & 105 & 274 & 114 \\
$1991-1995$ & 3,468 & NI & 236 & 118 & 258 & 125 \\
$1996-2000$ & 3,502 & 717 & 558 & 145 & 644 & 158 \\
2001 & 665 & 122 & 173 & 21 & 190 & 29 \\
2002 & 620 & 130 & 170 & 14 & 187 & 24 \\
2003 & 631 & 164 & 189 & 4 & 204 & 16 \\
2004 & 681 & 165 & 148 & 1 & 175 & 3 \\
2005 & 640 & 152 & 103 & & 21 & \\
$\geq 2006$ & 431 & 81 & 5 & & & \\
\hline
\end{tabular}

${ }^{1}$ TMI_75AUT $=$ TMI with a reliability of at least $75 \%$ of Austrian Fleckvieh bulls.

${ }^{2}$ TMI_75ALL $=$ TMI with a reliability of at least $75 \%$ of Austrian and German Fleckvieh bulls.

${ }^{3} \mathrm{CM} \_30$ and CM_50 = CM breeding value with a minimum reliability of 30 and 50\%, respectively; EREPRO_30 and EREPRO_50 = EREPRO breeding value with a minimum reliability of 30 and $50 \%$, respectively.

${ }^{4} \mathrm{NI}=$ no information; due to changes in the database, there is no reliable information about ownership of bulls before 1996 in Austria.

from 1,832 for CM to 2,978 for CYST. If the reliability is restricted to $50 \%$, the number is reduced dramatically by a further $70 \%$ (Table 6 ). The distribution of bulls according to their year of birth (Table 7) shows that high reliabilities of EBV for direct health traits are only achieved for second-crop bulls. The young bulls with a reliability of $\geq 50 \%$ are mainly from areas in Austria where farmer participation and veterinarian support are already high.

The average incidence level for the respective observation period is $9.8 \%$ for clinical mastitis, $5.0 \%$ for early reproductive disorders, $5.4 \%$ for CYST, and $2.4 \%$ for MF. Table 8 shows that although heritability is low, genetic variation exists. On average, $7 \%$ of the daughters of the TOP 20 bulls, based on a breeding value for mastitis, were diagnosed with mastitis within $150 \mathrm{~d}$ after calving. Among the offspring of the 20 worst bulls, the average was $16 \%$. Similar values were observed for other traits.

Fuerst et al. (2011) presented EBV correlations between health and other traits. Correlations were, for the most part, slightly negative with milk production but close to 0 with the TMI. The correlations were slightly positive with most of the functional traits, particularly with longevity.

Currently, EBV for direct health traits are not included in the TMI. A combination of direct health traits in the fertility index and a combination of CM, SCC, and type traits as correlated traits is being developed (Egger-Danner et al., 2011b).

Sufficient Data for Reliable Breeding Values. The challenge is to obtain a sufficient amount of reliable direct health data for breeding value estimation. As heritability is low, the amount of data needed is comparable to that required for other functional traits. One possibility is that direct health data are collected from all herds during routine performance recording, comparable to reporting inseminations or ease of calving. With genomic selection, a reduction in the number of test bulls is expected. Therefore, as long as data from the dairy herd recording system is collected on a broad scale and health reporting continues, the number of progeny per bull with health phenotypes will increase. Recently, most Austrian Fleckvieh breeding organizations have decided that in the future, the reporting of direct health traits shall be a compulsory part of performance reporting and will be included in the breeding program.

Alternatively, a second option is to concentrate on extensive reporting of different traits from a limited number of herds, so-called contract herds. The advantage of this is that heritability might be higher (Koenig et al., 2008; Swalve and König, 2010). Additionally, genotypes could be taken from these herds, subject to comprehensive recording. This data could be used to increase the reference population for genomic evaluations. This means that it is particularly important to

Table 8. Percentage of cows with at least 1 diagnosis of mastitis in the respective trait period for clinical mastitis $(\mathrm{CM})$, early reproductive disorders (EREPRO), cystic ovaries (CYST), and milk fever (MF), based on the 20 best and 20 worst bulls for each trait

\begin{tabular}{lrcrr}
\hline & \multicolumn{4}{c}{ Cows with diagnosis (\%) } \\
\cline { 2 - 5 } Item & CM & EREPRO & CYST & \multicolumn{1}{c}{ MF } \\
\hline Best 20 bulls & 7.32 & 2.14 & 1.84 & 1.78 \\
Worst 20 bulls & 16.51 & 8.87 & 12.22 & 10.67 \\
\hline
\end{tabular}


genotype complete herds and not just the genetically most interesting cows within herds.

Genomic Evaluation. To ensure favorable genetic response for fitness and health traits in the future, it is important that for these traits, genomic information can also be weighted appropriately within the TMI (Egger-Danner et al., 2011b).

Over the last $10 \mathrm{yr}$, between 650 and 750 Fleckvieh bulls have been tested in Austria and Germany each year. The Fleckvieh reference population for genomic evaluation currently has about 6,000 bulls (Emmerling and Edel, 2011). Presently, EBV for direct health traits per birth year with a minimum reliability of $30 \%$ are published for about 100 to 140 bulls (Table 7). Compared with the other traits, these are only about 20 to $30 \%$ of the Fleckvieh bulls tested in Germany and Austria every year. As functional traits are only included within genomic evaluation if the minimum reliability based on daughters is $30 \%$, the actual percentage is even lower. Assuming that the number of test bulls is decreasing due to genomic selection, it can be expected that in the future, Austria and Germany together will have a total of about 400 bulls each year. This would mean that relying only on bulls for genomic selection for health traits would require another $10 \mathrm{yr}$ to increase the reference population by about 4,000 bulls, assuming coverage comparable to the other functional traits in Germany and Austria. To decrease the time needed until genomic breeding values for direct health traits are available for Fleckvieh would mean that in addition to bulls, females from herds with comprehensive and reliable phenotyping for direct health traits would have to be genotyped. Goddard (2009), Hayes et al. (2009), Wiggans et al. (2010), and de Roos (2011) discussed the possibilities of implementing genomic evaluation from a female reference population. The number of genotyped cows depends on heritability, the effective population size, and the reliability of the desired breeding value. According to de Roos (2011), for a trait with a heritability of 0.1 , about 7 cows per 1 bull with 100 progeny would be needed. This would mean that for a reference population of 4,000 bulls, at least 28,000 cows with reliable phenotypes for direct health traits would need to be genotyped. As the heritability for most of the direct health traits is lower, the number of cows would be even greater.

\section{Implementation and Further Developments}

To ensure that diagnoses continue to be registered and used in management and breeding, information must be officially adopted into routine procedures by the relevant organizations. Animal health organizations in Austria have decided to officially recognize the health-monitoring program, which is an important milestone. Information based on performance reporting and health monitoring is now part of the evaluation process in supervised herds (Austrian Ministry of Health, 2010).

The Tyrolean Grey Association decided to make health trait monitoring compulsory for its members as early as 2008. The Austrian Fleckvieh (Simmental) Federation included health trait reporting in their breeding program in April 2010. In 2011, several other breeding organizations made the reporting of health traits compulsory for members of their organization.

Additional measures will be undertaken to increase the benefits for farmers and veterinarians. Genetic parameters have been estimated for Brown Swiss and Holstein as well. For routine genetic evaluation of direct health traits of the other breeds, available data are still limited.

To improve breeding and selection, one important step will be the inclusion of direct health traits into the TMI. Preliminary studies have already been undertaken (Fuerst et al., 2010; Egger-Danner et al., 2011b). Results show that with the inclusion of the direct health traits and their economic weight, the selection response for fertility and mastitis can be shifted toward a positive genetic gain.

\section{CONCLUSIONS}

The registration and use of direct health data are gaining importance worldwide. Measures to monitor and improve animal health and food safety are sensitive. Therefore, the full support of all involved partner organizations is essential. Obtaining the necessary cooperation can be a challenge but is also an opportunity to establish a joint system to share benefits and to efficiently use synergies. Diagnostic data provided by the farmers and breeding organizations are available for breeding and management purposes, but the information can also be used by veterinarians and animal health organizations. Besides a participative approach, an appropriate system of reporting and data storage, with guaranteed data security and obvious benefits for all stakeholders, is essential when establishing a system of health monitoring. We found that the process of motivating and informing program participants was a much greater challenge than setting up the technical requirements. It is especially important to convince opinion leaders at an early stage in the process. A regular supply of information to build up confidence and to communicate the benefits is a further key factor for success. Including the reporting of direct health data into routine procedures and having the support of opinion leaders in agricultural and veterinarian organi- 
zations are important for the sustainability of the program. Thus, legal frameworks for the documentation and use of diagnostic data are very valuable. To obtain a sufficient number of phenotypes for direct health traits, it is recommended to include registration of diagnostic data within regular performance recording, to increase the number of progenies per test bull, or to concentrate progenies of test bulls on farms with reliable health reporting. To ensure data quality and data quantity, it is important that different data sources and data reporting methods are considered. For an earlier availability of sufficient phenotypes and genotypes for genomic evaluation, the genotyping of females from herds with reliable health data reporting could be an option.Continuous health reporting with a high level of participation is a major challenge, which will be more easily sustained if a benefit for the different key players involved can be guaranteed.

\section{ACKNOWLEDGMENTS}

The authors gratefully acknowledge the collaborative work of the project partners in Austria [Federation of Austrian Cattle Breeders (Vienna), ZuchtData EDVDienstleistungen GmbH (Vienna, Austria), University of Natural Resources and Life Sciences Vienna, University of Veterinary Medicine Vienna, Chamber of Agriculture (Vienna, Austria), Chamber of Veterinarians (Vienna, Austria), animal health organizations, performance-reporting organizations, and breeding organizations] to establish a health monitoring system in cattle, and also thank all participating dairy farmers and veterinarians. The project was financed by the Federal Ministry of Agriculture, Forestry, Environment and Water Management (BMLFUW) of Austria, the Ministry of Health and the Federation of Austrian Cattle Breeders (ZAR); B. Fuerst-Waltl was financially supported by the Austrian Science Fund FWF (Elise Richter Project V43-B12).

\section{REFERENCES}

Aamand, G. P. 2006. Data collection and genetic evaluation of health traits in the Nordic countries. Br. Cattle Conf., Shrewsbury, UK. British Cattle Breeders Club, Holsworthy, UK.

Appuhamy, J. A. D. R. N., B. G. Cassell, and J. B. Cole. 2009. Phenotypic and genetic relationship of common health disorders with milk and fat yield persistencies from producer-recorded health data and test-day yields. J. Dairy Sci. 92:1785-1795.

Austrian Ministry of Health. 2010. Kundmachung des TGD-Programms Gesundheitsmonitoring Rind. Accessed May 30, 2011. http://www.bmg.gv.at/home/Schwerpunkte/Tiergesundheit/ Rechtsvorschriften/Kundmachungen/Kundmachung_des_TGD_ Programms_Gesundheitsmonitoring_Rind.

Cole, J.B., A.H. Sanders, and J.S. Clay. 2006. Use of producer-recorded health data in determining incidence risks and relationships between health events and culling. J. Dairy Sci. 89(Suppl. 1):10 (Abstr. M7) de Roos, A. P. W. 2011. Genomic selection in dairy cattle. Ph.D. Thesis. Wageningen University, Wageningen, the Netherlands.

Dempster, E. R., and I. M. Lerner. 1950. Heritability of threshold characters. Genetics 35:212-236.

Egger-Danner, C. 2011. Final project report "Health monitoring in cattle". April 15, 2011. Austrian Ministry of Health, Vienna, Austria.

Egger-Danner, C., B. Fürst-Waltl, W. Obritzhauser, A. Koeck, B. Grassauer, R. Janacek, C. Litzllachner, M. Mayerhofer, J. Miesenberger, F. Schallerl, G. Schoder, and A. Wagner. 2010a. Availability of health data - Challenges and key factors of success. Proc. 9th World Congr. Genet. Appl. Livest. Prod., Leipzig, Germany. Gesellschaft für Tierzuchtwissenschaften e.V., Gießen, Germany.

Egger-Danner, C., A. Koeck, W. Obritzhauser, C. Fuerst, and B. Fuerst-Waltl. 2009. Impact of health data quality on breeding efficiency in Austrian Fleckvieh cows. Page 411 in Book of Abstracts of the 60th Annu. Meeting of the EAAP, Barcelona, Spain. Wageningen Academic Publishers, Wageningen, the Netherlands.

Egger-Danner, C., W. Obritzhauser, B. Fuerst-Waltl, B. Grassauer, R. Janacek, F. Schallerl, C. Litzllachner, A. Koeck, M. Mayerhofer, J. Miesenberger, G. Schoder, A. Wagner, and K. Zottl. 2010b. Registration of health traits in Austria-Experience review. Page 69 in International Committee for Animal Recording (ICAR) Technical Series no. 14. Proc. of the 37th ICAR Biennial Session, Riga, Latvia. International Comittee for Animal Recording, Rome, Italy.

Egger-Danner, C., K. Stock, J. Cole, A. Bradley, J. Pryce, N. Gengler, L. Andrews, and E. Strandberg. 2011a. Registration of health traits - Strategies of phenotyping, aspects of data quality and possible benefits. Accessed Aug. 14, 2011. International Committee for Animal Recording (ICAR) Ann. Meeting, June, 21-23, 2011, Bourg-en-Bresse, France. http://www.icar.org/Documents/Bourgen-Bresse2011/Presentations/session\%202\%20-\%2022\%20pm/S2cChrista\%20Egger-DANNER.pdf.

Egger-Danner, C., A. Willam, C. Fuerst, H. Schwarzenbacher, and B. Fuerst-Waltl. 2011b. Impact of breeding strategies using genomic information on fitness and health. Page 125 in Book of Abstracts of the 62th Ann. Meeting of the EAAP, Stavanger, Norway. Wageningen Academic Publishers, Wageningen, the Netherlands.

Emmerling, R., and C. Edel. 2011. Genomische Selektion bei Fleckvieh und Braunvieh. Informationsveranstaltung zur Genomischen Selektion. March, 25, 2011, Salzburg. Accessed June 15, 2011. http:// www.zar.at/article/articleview/57834/1/5.

European Commission. 2007. A new Animal Health Strategy for the European Union (2007-2013) where "Prevention is better than cure." Accessed July 30, 2011. http://ec.europa.eu/food/animal/ diseases/strategy/animal_health_strategy_en.pdf.

Forshell, K. P., and O. Østerås. 2001. Trends in Norwegian udder health data during 1975 through 2000. Proc. of the 2nd International Symposium on Mastitis and Milk Quality. National Mastitis Council, Madison, WI.

Fuerst, C., A. Koeck, C. Egger-Danner, and B. Fuerst-Waltl. 2010. Phenotypic and genetic relationships between clinical mastitis and udder conformation traits in Austrian Fleckvieh cattle. Proc. 9th World Congr. Genet. Appl. Livest. Prod., Leipzig, Germany. Gesellschaft für Tierzuchtwissenschaften e.V., Gießen, Germany.

Fuerst, C., A. Koeck, C. Egger-Danner, and B. Fuerst-Waltl. 2011. Routine genetic evaluation for direct health traits in Austria and Germany. Interbull Meeting, Stavanger, Norway. Interbull Centre, Uppsala, Sweden.

Goddard, M. 2009. Genomic selection: Prediction of accuracy and maximisation of long term response. Genetica 136:245-257.

Groeneveld, E., M. Kovač, and N. Mielenz. 2008. VCE User's Guide and Reference Manual Version 6.0. Institute of Farm Animal Genetics, Neustadt, Germany.

Hayes, B. J., P. J. Bowman, A. C. Chamberlain, and M. E. Goddard 2009. Genomic selection in dairy cattle: Progress and challenges. J. Dairy Sci. 92:433-443.

Heringstad, B., Y. M. Chang, D. Gianola, and G. Klemetsdal. 2005. Genetic correlations between clinical mastitis, milk fever, ketosis and retained placenta within and between the first three lactations of Norwegian Red (NRF). Page 45 in Book of Abstracts of the 
56th Ann. Meeting of the EAAP, Uppsala, Sweden. Wageningen Academic Publishers, Wageningen, the Netherlands.

Heringstad, B., G. Klemetsdal, and T. Steine. 2003a. Selection response for clinical mastitis and protein yield in two Norwegian dairy cattle selection experiments. J. Dairy Sci. 86:2990-2999.

Heringstad, B., G. Klemetsdal, and T. Steine. 2007. Selection responses for disease resistance in two selection experiments with Norwegian red cows. J. Dairy Sci. 90:2419-2426.

Heringstad, B., R. Rekaya, D. Gianola, G. Klemetsdal, and K. A. Weigel. 2003b. Genetic change for clinical mastitis in Norwegian cattle: A threshold model analysis. J. Dairy Sci. 86:369-375.

Interbull. 2011. Description of national genetic evaluation systems for dairy cattle traits as applied in different Interbull member countries. Accessed July 30, 2011. http://www-interbull.slu.se/national_ges_info2/framesida-ges.htm.

Johansson, K., S. Eriksson, J. Pösö, M. Toivonen, U. S. Nielsen, J. A. Eriksson, and G. P. Aamand. 2006. Genetic evaluation of udder health traits for Denmark, Finland and Sweden. Interbull Bull. 35:92-96

Johansson, K., J. Pösö, U. S. Nielsen, J.-A. Eriksson, and G. P. Aamand. 2008. Joint genetic evaluation of other disease traits in Denmark, Finland and Sweden. Interbull Bull. 38:107-112.

Kelton, D. F., K. D. Lissemore, and R. E. Martin. 1998. Recommendations for recording and calculating the incidence of selected clinical diseases of dairy cattle. J. Dairy Sci. 81:2502-2509.

Koeck, A., C. Egger-Danner, C. Fuerst, W. Obritzhauser, and B. Fuerst-Waltl. 2010a. Genetic analysis of reproductive disorders and their relationship to fertility and milk yield in Austrian Fleckvieh dual-purpose cows. J. Dairy Sci. 93:2185-2194.

Koeck, A., B. Heringstad, C. Egger-Danner, C. Fuerst, and B. FuerstWaltl. 2010b. Comparison of different models for genetic analysis of clinical mastitis in Austrian Fleckvieh dual-purpose cows. J. Dairy Sci. 93:4351-4358

Koeck, A., B. Heringstad, C. Egger-Danner, C. Fuerst, P. Winter, and B. Fuerst-Waltl. 2010c. Genetic analysis of clinical mastitis and somatic cell count traits in Austrian Fleckvieh cows. J. Dairy Sci. 93:5987-5995.

Koeck, A., F. Miglior, D. F. Kelton, and F. S. Schenkel. 2012. Alternative somatic cell count traits to improve mastitis resistance in Canadian Holsteins. J. Dairy Sci. 95:432-439.

Koenig, S., K. Brügemann, and H. Simianer. 2008. Testherden in Zuchtprogrammen für Milchrinder. 2. Mitteilung: Strategien zur Findung von Testherden. Züchtungskunde 80:114-126.

Lidauer, M., I. Strandén, and E. Mäntysaari. 2008. MiX99-Mixed Model Equations Solver. Manual. Agrifood Research, Jokioinen, Finland.

Negussie, M., M. Lidauer, E. A. Mäntysaari, I. Stranden, J. Pösö, U. S. Nielsen, K. Johansson, J.-A. Eriksson, and G. P. Aamand. 2010. Combining test day SCS with clinical mastitis and udder type traits: A random regression model for joint genetic evaluation of udder health in Denmark, Finland and Sweden. Interbull Bull. 42:25-31.

Neuenschwander, T. F. O. 2010. Studies on disease resistance based on producer-recorded data in Canadian Holsteins. PhD Thesis. University of Guelph, Guelph, ON, Canada.

Nielsen, U. S., G. P. Aamand, and T. Mark. 2000. National genetic evaluation of udder health and other traits in Denmark. Interbull Bull. 25:143-150.
Østerås, O., H. Solbu, A. O. Refsdal, T. Roalkvam, O. Filseth, and A. Minsaas. 2007. Results and evaluation of thirty years of health recordings in the Norwegian dairy cattle population. J. Dairy Sci. 90:4483-4497.

Østerås, O., and L. Sølverød. 2005. Mastitis control systems: The Norwegian experience. Pages 91-101 in Mastitis in Dairy Production: Current Knowledge and Future Solutions. H. Hogeveen, ed. Wageningen Academic Publishers, Wageningen, the Netherlands.

Philipsson, J., and B. Lindhé. 2003. Experiences of including reproduction and health traits in Scandinavian dairy cattle breeding programmes. Livest. Prod. Sci. 83:99-112.

Pritchard, T. C., R. Mrode, M. P. Coffey, and E. Wall. 2011. Combination of test day somatic cell count and incidence of mastitis for the genetic evaluation of udder health. Interbull Meeting, Stavanger, Norway. Accessed Nov. 2, 2011. http://www.interbull.org/images/ stories/Pritchard.pdf.

Schwarzenbacher, H., W. Obritzhauser, B. Fuerst-Waltl, A. Koeck, and C. Egger-Danner. 2010. Health monitoring system in Austrian dual purpose Fleckvieh cattle: Incidences and prevalences. Page 145 in Book of Abstracts of the 61th Ann. Meeting of the EAAP, Heraklion, Greece. Wageningen Academic Publishers, Wageningen, the Netherlands.

Strandén, I., M. Lidauer, E. A. Mäntysaari, and J. Pösö. 2001. Calculation of Interbull weighting factors for the Finnish test day model. Interbull Bull. 26:78-79.

Swalve, H. H., and S. König. 2007. Testherden in Zuchtprogrammen für Milchrinder 1. Mitteilung: Allgemeine Überlegungen. Züchtungskunde 79:249-262.

Tier, B., and K. Meyer. 2004. Approximating prediction error covariances among additive genetic effects within animals in multipletrait and random regression models. J. Anim. Breed. Genet. 121:77-89.

Urioste, J. I., J. Franzén, J. J. Windig, and E. Strandberg. 2011. Genetic variability of alternative somatic cell count traits and their relationship with clinical and subclinical mastitis. Interbull Meeting, Stavanger, Norway. Accessed Nov. 2, 2011. http://www.interbull.org/images/stories/Urioste.pdf.

Visscher, P. M., and M. E. Goddard. 1993. Fixed and random contemporary groups. J. Dairy Sci. 76:1444-1454.

Wiggans, G. R., T. A. Cooper, and P. M. VanRaden., 2010. Cow adjustments for genomic predictions of Holstein and Jersey bulls. J. Dairy Sci. 93(E-Suppl. 1):533-534. (Abstr. 618)

ZuchtData. 2010. ZuchtData Jahresbericht, 2010. ZuchtData EDVDienstleistungen GmbH, Vienna. Accessed July 30, 2011. http:// www.zuchtdata.at/article/archive/25.

Zwald, N. R., K. A. Weigel, Y. M. Chang, R. D. Welper, and J. S. Clay. 2004a. Genetic selection for health traits using producerrecorded data. I. Incidence rates, heritability estimates, and sire breeding values. J. Dairy Sci. 87:4287-4294

Zwald, N. R., K. A. Weigel, Y. M. Chang, R. D. Welper, and J. S. Clay. 2004b. Genetic selection for health traits using producerrecorded data. II. Genetic correlations, disease probabilities, and relationships with existing traits. J. Dairy Sci. 87:4295-4302.

Zwald, N. R., K. A. Weigel, Y. M. Chang, R. D. Welper, and J. S. Clay. 2006. Genetic analysis of clinical mastitis data from onfarm management software using threshold models. J. Dairy Sci. $89: 330-336$ 